\title{
Burden of Dengue with Related Entomological and Climatic Characteristics in Surat City, Gujarat, India, 2011-2016: An Analysis of Surveillance Data
}

\author{
Viral R. Bajwala, ${ }^{1 \star}$ Denny John, ${ }^{2,3}$ Daniel Rajasekar, ${ }^{4}$ Alex Eapen, ${ }^{5}$ and Manoj V. Murhekar ${ }^{4}$ \\ ${ }^{1}$ Department of Health and Hospital, Surat Municipal Corporation, Surat City, India; ${ }^{2}$ Campbell South Asia, New Delhi, India; ${ }^{3}$ ICMR-National \\ Institute of Medical Statistics, New Delhi, India; ${ }^{4}$ National Institute of Epidemiology, Indian Council of Medical Research, Chennai, India;
}

${ }^{5}$ ICMR - National Institute of Malaria Research, Chennai, India

\begin{abstract}
We estimated the incidence of laboratory-confirmed dengue patients for Surat city, India, using surveillance data from 2011 to 2016 and described the related entomological indices and climatic factors. There was a rise in incidence from 1.5 to 17.6 per 100,000 population, as the numbers of notified cases have increased because of better surveillance system. The case notification was 1.3 times higher for the public sector than the private sector. The larval indices were below the transmission level (House index, Breteau index $<1 \%$ ). The median age of dengue patients was 20 years (IQR: $14-28)$, with a male to female ratio of 1.6:1. Five peripheral vector control units contributed to $1,013(41.4 \%)$ confirmed cases with rising incidence in other units also. The number of dengue patients peaked during post-monsoon. Spearman's correlation of vector density with humidity $\left(r_{s}=0.556\right)$, rainfall $\left(r_{s}=0.644\right)$, and number of cases $\left(r_{s}=0.708\right)$ suggested climate favorable for vector breeding. There is a good system of public-private coordination for dengue surveillance. However, there is a need to reassess the vector indices threshold for transmission in the city.
\end{abstract}

\section{INTRODUCTION}

Dengue is a viral disease transmitted by the bite of infected female mosquitoes mainly of the species Aedes aegypti and, to a lesser extent, Ae. albopictus. ${ }^{1}$ It has emerged as a major public health problem. It is estimated that annually 390 million dengue infections occur worldwide, of which $25 \%$ manifest clinically. ${ }^{2}$ Substantial increase in the number of cases has been reported in 2019 , with the majority $(85 \%)$ of the $1,049,000$ cases reported by Brazil, the Philippines, Mexico, Nicaragua, Thailand, Malaysia, and Colombia and autochthonous cases of dengue reported by France and Spain. ${ }^{3}$ An estimated 500,000 people with severe dengue require hospitalization each year worldwide, and about $2.5 \%$ of those affected succumb to the illness. ${ }^{1}$

Although the reported number of dengue cases in India has increased from 18,860 in 2011 to 101,192 in 2018, the case fatality ratio has declined from $3.3 \%$ in 1996 to $0.2 \%$ in $2018 .{ }^{4}$ An upsurge in the number of cases has also been observed for the Gujarat state, India, that contributed $7.5 \%$ cases in 2018 , the fourth highest in the country. ${ }^{4}$ The number of laboratoryconfirmed cases in Surat city, South Gujarat, also raised from 69 in 2011 to 1,002 in 2016 according to the surveillance data.

Vector surveillance and climatic factors are essential components to understand dengue dynamics. Vector surveillance helps to identify changes in the geographic distribution and density of the vectors, evaluate the control program, and guide vector control activities. ${ }^{5}$ Warm temperatures and high humidity increase the longevity of the adult mosquitoes and shorten the viral incubation period within the vector and its blood-feeding intervals, thus leading to increased transmission intensity. ${ }^{6}$ Precipitation provides aquatic habitats to immature forms of mosquitoes.

Estimating the epidemiologic burden of dengue in terms of prevalence and incidence helps for informed policy-making and monitoring the progress of disease control. ${ }^{7}$ The rising number of dengue cases within the city needed eco-epidemiological

\footnotetext{
${ }^{*}$ Address correspondence to Viral R. Bajwala, Department of Health and Hospital, Surat Municipal Corporation, H.No.4, Pooja Row house society, Jai Ambe Rd., Surat City 395009, India. E-mail: vrbdrvrb@ gmail.com
}

analysis that was not performed previously. In this study, we analyzed the surveillance data of 6 years (2011-2016) 1) to estimate the incidence of dengue and 2) describe the role of entomological indices related to immature forms of $A e$. aegypti and climatic factors for its transmission in the city.

\section{METHODS}

Study site and setting. The study was conducted in Surat city, India, that has a population of $44,66,826$ and a density of 13,680 persons per sq.km (census 2011). The vector-borne disease control unit of the Health and Hospital department of Municipal Corporation undertakes preventive and control activities of vector-borne diseases through 32 sub-administrative peripheral units (each assigned with defined population and geographical area). The unit is also identified as the central sentinel surveillance site for the city. In 2016, when the study was conducted, there were 42 urban primary health centers and two tertiary care hospitals in public sector, and 539 private hospitals.

Data collection. Dengue case surveillance data. We obtained the line list of probable and laboratory-confirmed dengue cases notified to central sentinel site by public and private institutes within the city from January 1, 2011 to December 21, 2016. A probable case of dengue fever was defined as an occurrence of fever of 2-7 days duration with two or more of the following clinical manifestations: headache, retro-orbital pain, myalgia, arthralgia, rash, and hemorrhagic manifestations. ${ }^{8}$ A case compatible with the earlier clinical description, along with demonstration of either $\lg \mathrm{M}$ antibody or dengue virus antigen NS1 or both by ELISA, was considered as a confirmed case. ${ }^{8}$ All probable cases were investigated for ELISA-based NS1 or IgM. Patients residing outside the city were excluded from the analysis. The information about age at diagnosis, gender, location of case patients within peripheral administrative units, the month of occurrence of dengue illness, date of onset of illness, date of sample collection, and method of diagnosis was extracted from the surveillance database.

Vector surveillance data. Routine vector surveillance and control activities within the city are carried out by the primary 
health workers of the peripheral units. They are assigned a defined population and geographical area within each unit. These workers are trained in identifying mosquito species and larvae, and mosquito habitats; reporting; and control measures in the community. They conduct house-to-house survey daily, to search for potential breeding sites such as the usual man-made water-storing containers and other unusual sites that become active during monsoon. They follow integrated vector management strategy ${ }^{5}$ for vector control that includes elimination or management of larval sources, larviciding with insecticides (temephos), use of larvivorous fish Gambusia affinis as a biological control agent, besides advocacy and legislation. Their movement is planned such that every house is repeated fortnightly. These activities occur throughout the year. However, when probable and confirmed patients are notified to the central sentinel surveillance site, the information is conveyed immediately to the respective peripheral unit under which the patient resides. On a priority basis, the concerned health worker visits the patient's house and conducts active search for fever patients, entomological survey, and control measures in the surrounding area. The compliance report of the activity is then sent back to the central unit. The report includes mosquito larval indices that estimate the density of immature Aedes mosquitoes viz House index (HI), defined as the percentage of houses infested with larvae and/or pupae; Container index $(\mathrm{Cl})$, defined as the percentage of waterholding containers infested with larvae and/or pupae; and the Breteau index $(\mathrm{Bl})$, defined as the number of positive containers per 100 houses inspected. For the purpose of analysis, we considered larval indices in the locality of laboratory-confirmed cases. The data about larval indices for 2011 were not available. We cross-checked the entomological indices in the database using formulas, and wrong values were corrected.

In addition, the system has insect collectors (ICs), each of whom is assigned to a specific peripheral unit and subsequently fixed geographical area within these units, to collect adult mosquitoes routinely. Five houses within this area are fixed sentinel sites, whereas the other five houses are randomly selected by ICs for vector collection. Every morning between 7:30 and 10:30 AM, ICs move into the houses with flashlights to search resting mosquitoes both indoor and outdoor, and catch them with mouth aspirators, spending approximately 15 minutes in each house. Collected mosquitoes are identified for species and expressed as female Ae. aegypti vector density per 10 man-hour. We collected these data from the central surveillance unit.

Climate data. We considered mean temperature $\left({ }^{\circ} \mathrm{C}\right)$, relative humidity (\%), and precipitation (rainfall in $\mathrm{mm}$ ) as climatic parameters affecting vector ecology. We obtained a historic database of these parameters from Tutiempo Network, SL, ${ }^{9}$ and the collector office website, for the year 2011 through 2016. Seasons were defined as winter period from January to February, pre-monsoon period from March to May, monsoon period from June to September, and post-monsoon period from October to December according to the Indian meteorological department. ${ }^{10}$

Data analysis. We estimated the case notification rate from public and private facilities as the number of new cases notified in a given year per 100,000 population. We calculated the mean and median duration between the onset of fever and sample collection for laboratory-confirmed cases after excluding the missing dates from the analysis. Age was summarized as mean with SD and median with interquartile range. Data were plotted in the form of graphs for the seasonal distribution of cases.

We calculated the incidence of dengue considering the number of new laboratory-confirmed cases reported during a particular year as the numerator and population of Surat city as the denominator. The unit-specific population was available from the central surveillance unit from 2012 onward and was directly used to calculate unit-specific incidence that was later plotted on the area map of Surat city using Epi info software. However, it did not have age and gender bifurcation. So, first we estimated the population using the following equation assuming the linear growth of population. ${ }^{11}$

$P_{\text {specific year }}=P_{2011}(1+r t)$, where $P_{2011}$ is the census population of year 2011, $r$ is the growth rate $(r=0.0552$ for Surat city), and $t$ is the time period between specific year and 2011.

Subsequently, we applied age- and gender-specific proportions to the estimated population of each year to derive the age- and gender-specific population.

Entomological indices for laboratory-confirmed cases were expressed as mean and median and stratified according to seasons. We plotted graphs for climatic factors and vector density. We calculated Spearman's correlation coefficient $\left(r_{\mathrm{s}}\right)$ to find out the correlation between temperature $\left({ }^{\circ} \mathrm{C}\right)$, relative humidity (\%), number of rainy days, and laboratory-confirmed cases with vector density.

Human subject protection. We used surveillance data without individual identifiers available with Central Surveillance Unit.

\section{RESULTS}

Case notification. A rising trend in case notification of probable and laboratory-confirmed dengue cases was observed from 2011 to 2016 (Table 1). A total of 22,101 dengue cases were notified during this period with a peak in 2016 (43.6\% from private and $56.4 \%$ from public sector). Of these, 2,446 (11\%) were laboratory confirmed, including 546 (5.7\%) cases from private sector and 1,900 (15.2\%) cases from public sector. The rest were tested negative and classified as probable cases.

Laboratory confirmation. Of 2,446 laboratory-confirmed cases, 1,220 (49.9\%) were positive for IgM antibodies, 1,002 (40.9\%) for NS1 antigen, and 224 (9.2\%) for both (Table 2). Information about the date of onset of fever and sample collection was available for 2,003 (82\%) case-patients. The median duration between the onset of fever and blood collection for serology was 4 days (IQR: 3-7). A comparison of NS1 antigen detection and IgM ELISA for diagnosis of dengue based on this duration is detailed in Table 3.

Distribution of cases. The incidence of laboratory-confirmed cases increased from 1.5 in 2011 to 17.6 per 100,000 population in 2016, with a rising trend in both age- and gender-specific incidence (Table 4). People aged between 16 and 30 years followed by those aged between 4 and 15 years were more affected than those in other age-groups (Table 4). Compared with previous years, the median age has reduced to 20 years from the year 2013. The male: female ratio was 1.6:1.

The incidence of dengue by peripheral units is given in Figure 1. We observed the rising trend in all 32 units. However, the incidence of dengue was higher in five units, which accounted for $41.4 \%$ of the total laboratory-confirmed cases in Surat. Besides, three more units emerged with an incidence 
TABLE 1

Case notification rate for dengue according to the type of facilities in Surat city, Gujarat, India, 2011-2016 (notification rate expressed as new cases per 100,000 population).

\begin{tabular}{|c|c|c|c|c|c|c|c|c|c|c|}
\hline \multirow[b]{2}{*}{ Year } & \multirow[b]{2}{*}{ Population } & \multicolumn{3}{|c|}{ Probable cases } & \multicolumn{3}{|c|}{ Laboratory-confirmed cases } & \multicolumn{3}{|c|}{ Total cases } \\
\hline & & Private ( $n$, rate) & Public ( $n$, rate) & Total ( $n$, rate) & Private ( $n$, rate) & Public ( $n$, rate) & Total ( $n$, rate) & Private ( $n$, rate) & Public ( $n$, rate) & Total $(n$, rate $)$ \\
\hline 2011 & $4,466,826$ & $745(16.7)$ & 769 (17.2) & $1,514(33.9)$ & $10(0.2)$ & $59(1.3)$ & $69(1.5)$ & 755 (16.9) & $828(18.5)$ & $1,583(35.4)$ \\
\hline 2012 & $4,713,813$ & $1,075(22.8)$ & $948(20.1)$ & $2,023(42.9)$ & $41(0.9)$ & $126(2.7)$ & $167(3.5)$ & $1,116(23.7)$ & $1,074(22.8)$ & $2,190(46.5)$ \\
\hline 2013 & $4,960,800$ & $1,227(24.8)$ & 989 (19.9) & $2,216(44.7)$ & $37(0.7)$ & 307 (6.2) & 344 (6.9) & $1,264(25.5)$ & $1,296(26.1)$ & $2,560(51.6)$ \\
\hline 2014 & $5,207,787$ & $943(18.2)$ & 1,727 (33.0) & $2,670(51.2)$ & $65(1.2)$ & $298(5.7)$ & $363(7)$ & $1,008(19.4)$ & $2,025(38.9)$ & 3,033 (58.2) \\
\hline 2015 & $5,454,774$ & $1,755(32.2)$ & $2,774(50.8)$ & $4,529(83)$ & $136(2.5)$ & $365(6.7)$ & $501(9.2)$ & $1,891(34.7)$ & $3,139(57.5)$ & 5,030 (92.2) \\
\hline 2016 & $5,701,761$ & 3,339 (58.5) & $3,364(59)$ & 6,703 (117.5) & 257 (4.5) & 745 (13.1) & $1,002(17.6)$ & $3,596(63.1)$ & 4,109 (72.1) & 7,705 (135.1) \\
\hline
\end{tabular}

higher than that of Surat city from 2014. Finally, incidence in other six units raised from less than one case in 2012 to more than 3.5 cases per 100,000 population in subsequent years.

Although confirmed dengue patients were reported throughout the year, the incidence peaked during September and October. In 2016, a peak was noticed in November also (Figure 2).

Vector indices. The median number of houses surveyed around every laboratory-confirmed patient was 163 (IQR: 136-288) (Table 5). The median $\mathrm{HI}$ and $\mathrm{BI}$ were $0.7 \%$ (IQR: 0.3-1.1) and the median $\mathrm{Cl}$ was $0.3 \%$ (IQR: $0.1-0.5)$ for the city throughout the study period (Table 5). With the progression of the season during the year, median indices increased with maximum indices observed during monsoon followed by a post-monsoon period (Supplemental Table 1). The median female Ae. aegypti vector density was 0.8 per 10 man-hour, with a range from 0.3 to 3.2 throughout the study period (Table 5). The peak female vector density was observed during August, September, and October, that is, during monsoon and early post-monsoon period (Figure 2 ).

Climate and vector density. The climatic parameters are detailed in Table 5. We observed a drop of average $2^{\circ} \mathrm{C}$ from the beginning of monsoon in June toward the end of the season in September. The relative humidity peaked in July and August (Figure 3). The peak density of Ae. aegypti coincided with the increase in relative humidity (Figure 3 ), peak in the number of rainy days (Figure 3 ), and drop in atmospheric temperature during monsoon season (Figure 3 ). The correlation of female $A e$. aegypti vector density with humidity $\left(r_{s}=0.551\right)$, rainfall $\left(r_{s}=\right.$
0.642), and laboratory-confirmed dengue cases $\left(r_{s}=0.696\right)$ was significant at $P=0.01$.

\section{DISCUSSION}

Our analysis of surveillance data of dengue provided an estimate of the burden and epidemiology of disease within the city. We observed four times increase in the total case notification rate for 2016 compared with 2011. The disease was predominantly affecting young males and school-aged children with widening of the geographical distribution. Although dengue cases occurred throughout the year, peak in number was observed in the post-monsoon season. Entomological indices were low in the city, and female Ae. aegypti density positively correlated with humidity, rainfall, and laboratoryconfirmed cases.

The rising trend of dengue case notification could be due to active efforts made by the program managers in involving the private and public sectors for case notification. First, primary health centers of Surat Municipal Corporation (SMC) collect the information about patients suffering from various communicable diseases daily from identified sentinel private hospitals and forward it to the Integrated Disease Surveillance Program cell. In the case of dengue, this information is disseminated to the central vector-borne diseases control (VBDC) unit and subsequently to the concerned peripheral (VBDC) unit for preventive measures. Second, one person in all peripheral VBDC units is designated to collect information

TABLE 2

Descriptive statistics of the laboratory-confirmed dengue patients notified in Surat city, Gujarat, India, 2011-2016

\begin{tabular}{|c|c|c|c|c|c|c|c|}
\hline Variable & $2011 n=69(\%)$ & $2012 \mathrm{n}=167(\%)$ & $2013 n=344(\%)$ & $2014 n=363(\%)$ & $2015 \mathrm{n}=501(\%)$ & $2016 n=1,002(\%)$ & $\begin{array}{c}2011-2016 \\
n=2,446(\%)\end{array}$ \\
\hline Mean age \pm SD (years) & $21.2 \pm 12.5$ & $22.6+11.2$ & $22.3+12$ & $21.4+11.3$ & $21.8+11.5$ & $21.4+12.7$ & $21.7 \pm 12$ \\
\hline Median age (IQR) (years) & $21(12-25)$ & $22(16-28)$ & $20(15-30)$ & $20(14-28)$ & $20(14-28)$ & $20(12-28)$ & $20(14-28)$ \\
\hline \multicolumn{8}{|l|}{ Gender } \\
\hline Male & $45(65.2)$ & $94(56.3)$ & $212(61.6)$ & $215(59.2)$ & 315 (62.9) & $626(62.5)$ & $1,507(61.6)$ \\
\hline Female & $24(34.8)$ & $73(43.7)$ & 132 (38.4) & $148(40.8)$ & $186(37.1)$ & $376(37.5)$ & $939(38.4)$ \\
\hline \multicolumn{8}{|c|}{ Duration between onset of fever and blood collection for serology (days) } \\
\hline Mean \pm SD & $6 \pm 2.7$ & $6.6+3.4$ & $5.9+3.5$ & $5.2+3.4$ & $5.2+5.4$ & $4.9+3.1$ & $5.2 \pm 3.8$ \\
\hline Median (IQR) & $5(4-7)$ & $6(5-7)$ & $5(4-7)$ & $5(3-7)$ & $4(3-6)$ & $4(3-6)$ & $4(3-7)$ \\
\hline \multicolumn{8}{|l|}{ Laboratory diagnosis } \\
\hline NS1 & - & - & $67(19.5)$ & $159(43.8)$ & $257(51.3)$ & $519(51.8)$ & $1,002(40.9)$ \\
\hline IgM antibody & $69(100)$ & $167(100)$ & $258(75)$ & $160(44.1)$ & $184(36.7)$ & $382(38.1)$ & $1,220(49.9)$ \\
\hline Both & - & - & $19(5.5)$ & $44(12.1)$ & $60(12)$ & $101(10.1)$ & $224(9.2)$ \\
\hline \multicolumn{8}{|l|}{ Patients notified according to facility type* } \\
\hline $\begin{array}{l}\text { Government medical college and } \\
\text { hospital }\end{array}$ & $41(59.4)$ & $87(52)$ & $182(52.9)$ & $193(53.2)$ & $208(41.5)$ & 313 (31.2) & $1,024(41.9)$ \\
\hline $\begin{array}{l}\text { Health facilities from Surat municipal } \\
\text { corporation }\end{array}$ & $18(26.1)$ & $39(23.4)$ & $126(36.6)$ & $105(28.9)$ & $156(31.1)$ & $432(43.1)$ & $876(35.8)$ \\
\hline Private health facilities & $10(14.5)$ & $41(24.6)$ & $36(10.5)$ & $65(17.9)$ & $137(27.4)$ & $257(25.7)$ & $546(22.3)$ \\
\hline
\end{tabular}


TABLE 3

Comparison of NS1 antigen detection and IgM ELISA for diagnosis of dengue based on the duration between fever onset and sample collection for the dengue patients notified in Surat city, Gujarat, India, 2011-2016

\begin{tabular}{|c|c|c|c|c|}
\hline Duration (days) & $\lg M$ & $N S 1^{*}$ & Both & Total \\
\hline \multicolumn{5}{|c|}{ Probable cases (tested negative) } \\
\hline & $n=5,817, \%$ & $n=4,263, \%$ & $n=1,409, \%$ & $N=11,489, \%$ \\
\hline $1-5$ & $1,458(25)$ & $3,216(75.4)$ & $819(58.1)$ & $5,493(47.8)$ \\
\hline $6-10$ & $3,460(59.5)$ & $958(22.5)$ & 479 (34) & $4,897(42.6)$ \\
\hline$>10$ & 899 (15.5) & $89(2.1)$ & $111(7.9)$ & 1,099 (9.6) \\
\hline \multicolumn{5}{|c|}{ Laboratory-confirmed cases (tested positive) } \\
\hline & $n=898, \%$ & $n=893, \%$ & $n=212, \%$ & $N=2003, \%$ \\
\hline $1-5$ & $257(28.6)$ & $642(71.9)$ & 107 (50.5) & $1,006(50.2)$ \\
\hline $6-10$ & $530(59)$ & $224(25.1)$ & 89 (42) & $843(42.1)$ \\
\hline$>10$ & $111(12.4)$ & $27(3)$ & $16(7.5)$ & $154(7.7)$ \\
\hline
\end{tabular}

about dengue cases from private hospitals daily. There is a system of cross notification of cases between these units. Finally, all the hospitals (public and private) within the city are required to directly notify the cases to the central surveillance unit. The rise in dengue incidence could be a result of the increasing notification. It should be noted that the notification from the public sector was 1.3 times higher than that from the private sector, which is much larger and where most people seek treatment. ${ }^{12,13}$

Early laboratory confirmation of dengue can be lifesaving to prevent progression to severe dengue and death in a short duration. ${ }^{5}$ Almost $50 \%$ of patients had their blood samples collected within the first 5 days of fever, suggesting a need to increase diagnosis in the early phase. Although guidelines ${ }^{8}$ suggest testing for NS1Ag ELISA in the first 5 days of illness and for IgM antibodies beyond that, we observed that in some cases NS1 antigen was detected in patients beyond 5 days of fever onset, whereas IgM antibody appeared within 5 days of fever onset. Therefore, it is likely to miss the diagnosis using a single test.

The age-group of 16-30 years (median age 20 years) was most commonly affected, and this finding is consistent with other Indian studies. ${ }^{14,15}$ The study from Vietnam ${ }^{16}$ and Bra$\mathrm{zil}^{17}$ reported that the number of symptomatic patients increases as age advances and that young adult is more likely to manifest clinical dengue than children, with subsequent increase in their case reporting and notification.

The finding of male predominance for dengue in the current study is consistent with other studies. ${ }^{14,15,18}$ This genderrelated difference in incidence could be due to differences in places of exposure due to the nature of the occupation, movement of the people, or difference in utilization of health services, thereby influencing reporting. This hypothesis, however, needs further exploration.

In the present study, the peak number of cases was recorded in the post-monsoon period, a finding similar to study in south Gujarat, ${ }^{19}$ and elsewhere. ${ }^{20}$ The presence of some serologically positive cases even during dry months in this study could probably be reflective of the year-round activity of the dengue vector. One possible explanation is that $95 \%$ of the Surat population is covered with the piped network by SMC to supply water for usage at the consumer level. ${ }^{21}$ Municipal water is made available during fixed hours in a day and is stored either in overhead, underground, and ground tanks or plastic containers like barrels and drums by city dwellers. These containers may act as perennial potential breeding spots when open or covered loosely. There is a possibility of differences in availability and utilization of these containers based on season, with more utilization during summer and by people of lower socioeconomic strata. With the onset of rainfall, water stagnation and breeding in other naturally open secondary foci, such as discarded tires, tree holes, water bowls for birds and animals, drainage lids, coconut shells, flower pots, blocked rooftop gutters, faulty parapet around water tanks, and collection of waste on the terrace has been observed by the primary health workers of the city. A detailed ecological study in the future can help risk mapping of areas based on the availability of these potential natural, man-made, and discarded containers for targeted interventions.

An area is defined as high risk for the spread of dengue if $\mathrm{HI}>10 \%$ and $\mathrm{BI}>50 \%$, whereas low risk if $\mathrm{HI}<1 \%$ and $\mathrm{BI}<5 \% .^{22,23}$ Lower vector indices in Surat city could be on account of robust vector control measures taken by program

TABLE 4

Age- and gender-specific incidence (I) of the laboratory-confirmed dengue per 100,000 population in Surat city, Gujarat, India, 2011-2016

\begin{tabular}{|c|c|c|c|c|c|c|c|c|c|c|c|c|}
\hline & $\begin{array}{c}\text { Cases/ } \\
\text { population }\end{array}$ & 2011 & Cases/population & 2012 & Cases/population & 2013 & Cases/population & 2014 & Cases/population & 2015 & $\begin{array}{c}\text { Cases/ } \\
\text { population }\end{array}$ & 2016 \\
\hline \multicolumn{13}{|l|}{ Age-group (years) } \\
\hline $0-3$ & 308,092 & 6 & $7 / 325,128$ & 2.2 & 53 & 3.2 & 99 & 3.3 & 14 & 3.7 & 270 & 7.6 \\
\hline $4-15$ & $17 / 933,680$ & 1.8 & $31 / 985,307$ & 3.1 & $84 / 1$, & 8.1 & $101 / 1,0$ & 9.3 & 143/1, & 12.5 & $322 / 1$, & 27.0 \\
\hline $16-30$ & $37 / 1,557,812$ & 2.4 & $98 / 1$, & 6.0 & 183/1, & 10.6 & $188 / 1,8$ & 10.4 & $252 / 1$ & 13.2 & 497 & 23.4 \\
\hline $31-$ & 247 & 0.5 & $23 / 1$, & 2.2 & 3,082 & 4.7 & $50 / 1$ & 4.3 & $70 / 1,223,918$ & 5.7 & $134 / 1,279,336$ & 10.5 \\
\hline $46-60$ & 446,587 & 1.1 & 281 & 1.5 & $9 / 4$ & 1.8 & $11 / 5$ & 2.1 & $18 / 4$ & 3.3 & 055 & 6.0 \\
\hline$>60$ & & 0.0 & & 0.0 & & 2.5 & & 0.5 & & 9 & & 4.4 \\
\hline Age not specified & $0 / 39,287$ & 0.0 & $1 / 41,458$ & 2.4 & 632 & 0 & 803 & & $2 / 47,977$ & 4.2 & $7 / 50,148$ & 14.0 \\
\hline \multicolumn{13}{|l|}{ Gender } \\
\hline Mal & 5 & 1.8 & & 3.5 & & 7.5 & & 7.3 & & 10.1 & & 19.3 \\
\hline Female & $24 / 1,923,681$ & 1.2 & $73 / 2,030,048$ & 3.6 & $132 / 2,136,415$ & 6.2 & $148 / 2,242,783$ & 6.6 & $186 / 2,349,150$ & 7.9 & $376 / 2,455,517$ & 15.3 \\
\hline Surat city & $69 / 4,466,826$ & 1.5 & $167 / 4,713,813$ & 3.5 & $344 / 4,960,800$ & 6.9 & $363 / 5,207,787$ & 7.0 & $501 / 5,454,774$ & 9.2 & $1,002 / 5,701,761$ & 17.6 \\
\hline
\end{tabular}



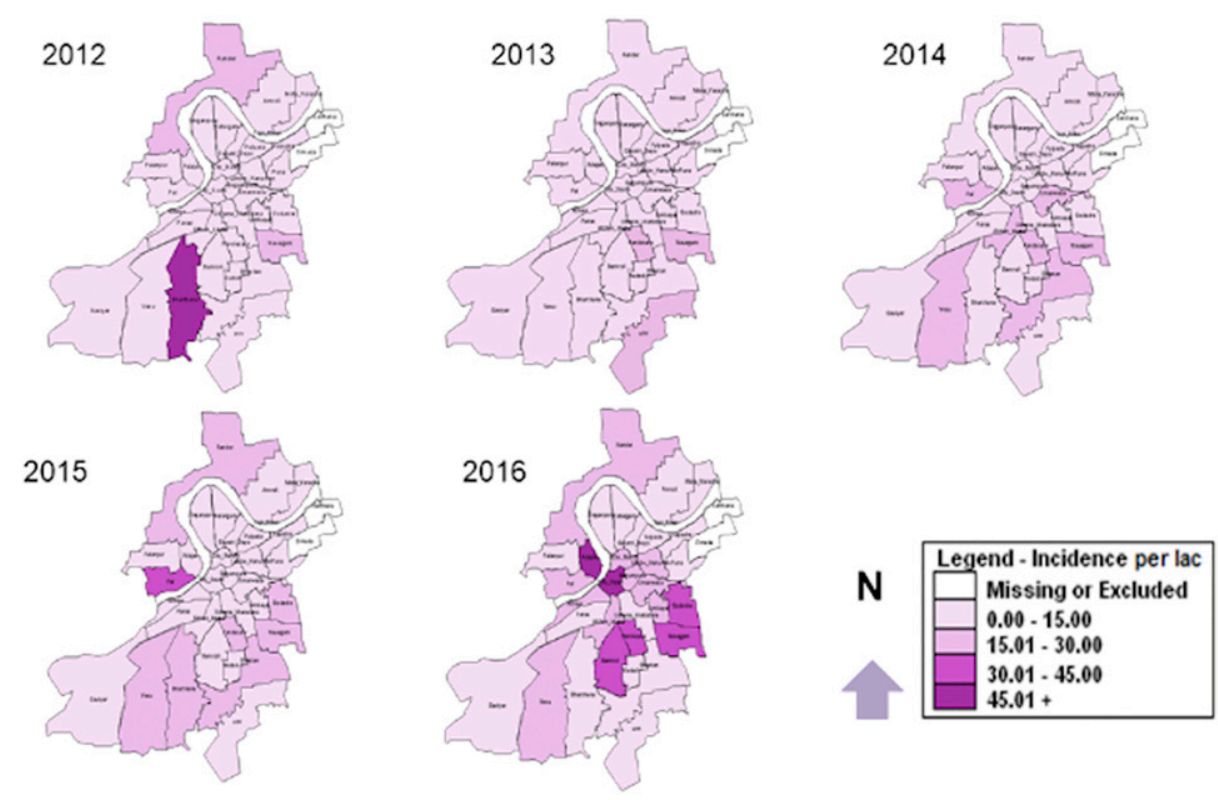

FIGURE 1. Incidence of dengue per 100,000 population residing within the geographical boundary of peripheral VBDCP units in Surat city, Gujarat, India, 2012-2016. This figure appears in color at www.ajtmh.org.

managers routinely and after a case of dengue is notified. Another reason for lower indices could be due to the limitation in the functionality of vector surveillance. It should be noted that in a controlled setting operated by the local health staff, some of the contingencies is expected to happen, and it is all based on the expertise, hands-on technical know-how, the systematic sampling strategy, the area covered, and possibility of reporting bias. Such limitation is the integral part of any surveillance system. ${ }^{18}$

Dengue transmission in the presence of low vector indices is explained by these facts. First, in the present study, we used data for vector indices that were collected from residential areas, although there is growing evidence of many infections occurring due to the mosquito bites at remote places like other houses, schools, and workplaces. ${ }^{24,25}$ Second, using traditional thresholds to determine transmission is unreliable, ${ }^{26}$ as dengue transmission is reported at $\mathrm{HI}$ level near $1 \%,{ }^{27,28} \mathrm{a}$ finding similar to our study. Third, dengue transmission does not occur at a fixed entomologic threshold, but it depends on other factors such as seroprevalence, mosquito density, and climate $^{29}$; macro-determinant factors such as population density, unplanned settlements, solid waste collections, and water supply; micro-determinants such as host susceptibility, occupation, and health condition; and vector-related factors such as high density and survival of infected female mosquitoes beyond extrinsic incubation period (EIP). ${ }^{30}$

Variation in climatic parameters in different seasons affects vector ecology and virus replication. Temperature affects the development of immature forms, vector body size, and feeding behavior. ${ }^{31}$ Temperature in the lower range $\left(\sim 17-18^{\circ} \mathrm{C}\right)$ limits disease transmission through its effect on the EIP of the virus, whereas at higher range temperatures $\left(\sim 35^{\circ} \mathrm{C}\right.$, depending on the vector species), it does so by limiting mosquito survival. ${ }^{32}$ The overall mean temperature remains between $20.5^{\circ} \mathrm{C}$ and

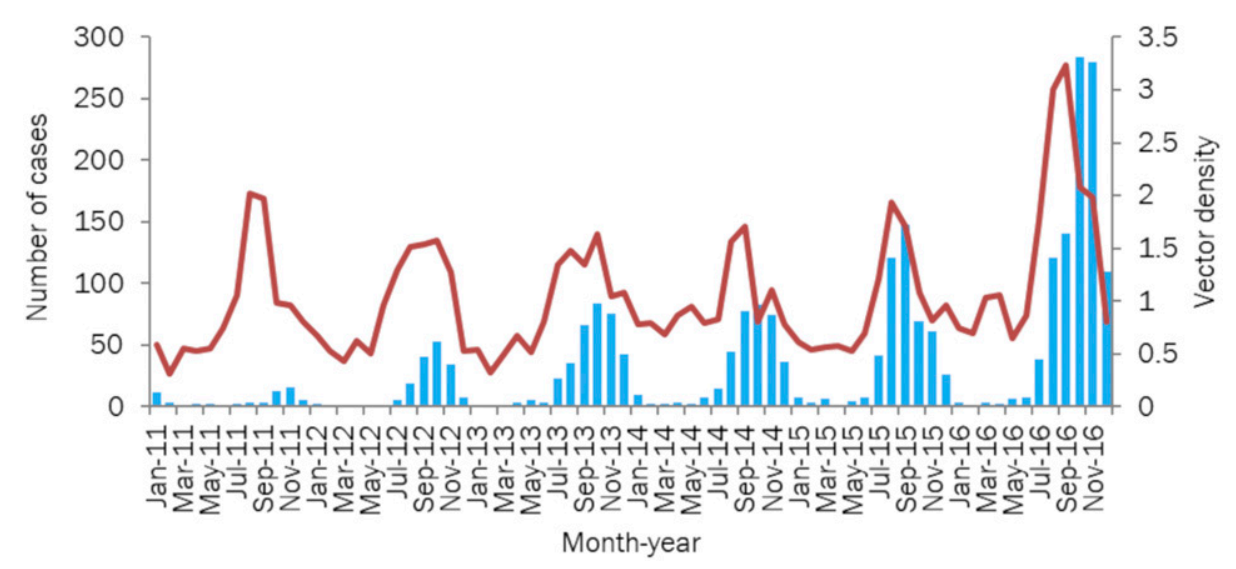

FIGURE 2. Temporal distribution of laboratory-confirmed cases of dengue and female Aedes aegypti vector density (per 10 man-hour) in Surat city, Gujarat, India, 2011-2016. This figure appears in color at www.ajtmh.org. 
TABLE 5

Entomological and climatic characteristics of the laboratory-confirmed dengue patients notified in Surat city, Gujarat, India, 2011-2016

\begin{tabular}{|c|c|c|c|c|c|c|c|}
\hline Variable & 2011 & 2012 & 2013 & 2014 & 2015 & 2016 & $2011-2016$ \\
\hline \multicolumn{8}{|l|}{ Entomological indices } \\
\hline \multicolumn{8}{|l|}{ Houses surveyed } \\
\hline Mean \pm SD & - & $254 \pm 202.9$ & $290.3 \pm 329.4$ & $238.2 \pm 181.3$ & $222.6 \pm 152.6$ & $210.8 \pm 151.9$ & $237.2 \pm 205$ \\
\hline Median (IQR) & - & $180(131-304)$ & $209(143-309)$ & $158(138-302)$ & $163(136-288)$ & $155(134-240)$ & $163(136-288)$ \\
\hline \multicolumn{8}{|c|}{ 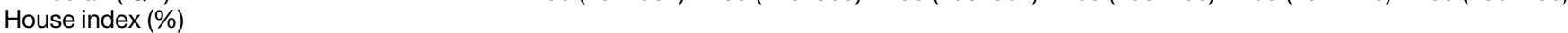 } \\
\hline Mean \pm SD & - & $1 \pm 1.5$ & $0.8 \pm 0.8$ & $0.8 \pm 1$ & $0.8 \pm 1$ & $0.9 \pm 0.7$ & $0.9 \pm 1$ \\
\hline Median (IQR) & - & $0.7(0.3-1.4)$ & $0.7(0.3-0.9)$ & $0.7(0.2-1)$ & $0.7(0.3-1)$ & $0.7(0.5-1.3)$ & $0.7(0.3-1.1)$ \\
\hline \multicolumn{8}{|l|}{ Breteau index (\%) } \\
\hline Mean \pm SD & - & $1.2 \pm 1.7$ & $0.8 \pm 0.8$ & $1 \pm 3.5$ & $0.9 \pm 2.5$ & $1 \pm 3.3$ & $1 \pm 2.7$ \\
\hline Median (IQR) & - & $0.7(0.3-1.4)$ & $0.7(0.3-0.9)$ & $0.7(0.2-1)$ & $0.7(0.3-1)$ & $0.7(0.5-1.3)$ & $0.7(0.3-1.1)$ \\
\hline \multicolumn{8}{|l|}{ Container index (\%) } \\
\hline Mean \pm SD & - & $0.6 \pm 1$ & $0.3 \pm 0.4$ & $0.5 \pm 1.6$ & $0.4 \pm 1$ & $0.5 \pm 2.3$ & $0.5 \pm 1.5$ \\
\hline Median (IQR) & - & $0.3(0.1-0.6)$ & $0.3(0.1-0.4)$ & $0.3(0.1-0.4)$ & $0.3(0.1-0.5)$ & $0.3(0.2-0.5)$ & $0.3(0.1-0.5)$ \\
\hline $\begin{array}{l}\text { Median (IQR) vector density } \\
\text { per } 10 \text { man-hour }\end{array}$ & $0.8(0.6-1)$ & $0.8(0.5-1.4)$ & $0.9(0.5-1.4)$ & $0.8(0.8-1)$ & $0.8(0.6-1.5)$ & $1(0.8-2)$ & $0.8(0.6-1.3)$ \\
\hline \multicolumn{8}{|l|}{ Climatic characteristics } \\
\hline Temperature ${ }^{\circ} \mathrm{C}($ mean $\pm \mathrm{SD})$ & $27.2 \pm 2.9$ & $27 \pm 3.1$ & $27 \pm 2.6$ & $27.8 \pm 3$ & $27.7 \pm 2.9$ & $27.6 \pm 2.7$ & $27.4 \pm 2.8$ \\
\hline $\begin{array}{l}\text { Relative humidity (\%), } \\
\text { mean } \pm \text { SD }\end{array}$ & $67.8 \pm 14$ & $66.4 \pm 14$ & $67.8 \pm 14.8$ & $66.2 \pm 12$ & $65.9 \pm 12$ & $66.3 \pm 14.4$ & $66.7 \pm 13$ \\
\hline $\begin{array}{l}\text { Rainfall }(\mathrm{mm}) \text {, mean } \pm S D \\
\text { Number of rainy days }\end{array}$ & $\begin{array}{c}254.8 \pm 160.6 \\
70\end{array}$ & $\begin{array}{c}184 \pm 176.7 \\
64\end{array}$ & $\begin{array}{c}427 \pm 253.7 \\
77\end{array}$ & $\begin{array}{c}241.3 \pm 185.6 \\
50\end{array}$ & $\begin{array}{c}222.2 \pm 152.9 \\
34\end{array}$ & $\begin{array}{c}192.2 \pm 109.3 \\
55\end{array}$ & $\begin{array}{l}254 \pm 182.9 \\
350\end{array}$ \\
\hline
\end{tabular}

$31.6^{\circ} \mathrm{C}$ in the city suitable for vector ecology. A drop in the average temperature during monsoon season as observed in the present study prevents evaporation of water in aquatic habitats for immature form, thereby providing an environment suitable for breeding. These biological facts are supported by the positive correlation of climatic factors, and vector density in the present study suggests climate as a favorable factor for vector ecology in the city.

The present findings should be interpreted within the context of some limitations. First, our incidence calculation was based exclusively on the laboratory-confirmed dengue cases. There is also a possibility of underreporting as observed in these studies. ${ }^{2,33,34}$ The incidence that we calculated, thus, could be an underestimate. Second, the pupal index helps to identify the type of containers with the highest rates of adult mosquito emergence, thereby targeting such containers for source reduction or other vector control interventions. However, data on the pupal index are not routinely collected. Third, we presented ecological findings that are applicable at the city level and cannot make inferences concerning the causative relationships at the individual patient level. Fourth, we could not estimate severity due to dengue as this information was not available. Severity has a direct implication on clinical case management, triaging, and cost of treatment. ${ }^{35}$

Based on the findings of the study, it is recommended that the health system of the city should continue dengue surveillance through public-private coordination. There is a need to capture essential information such as severity and pupal indices in surveillance data. Entomological surveillance can be planned by the appropriate sampling strategy ${ }^{5}$ to reassess the vector indices threshold for dengue transmission in the city. Early warning and prediction models involving all risk factors can be developed to

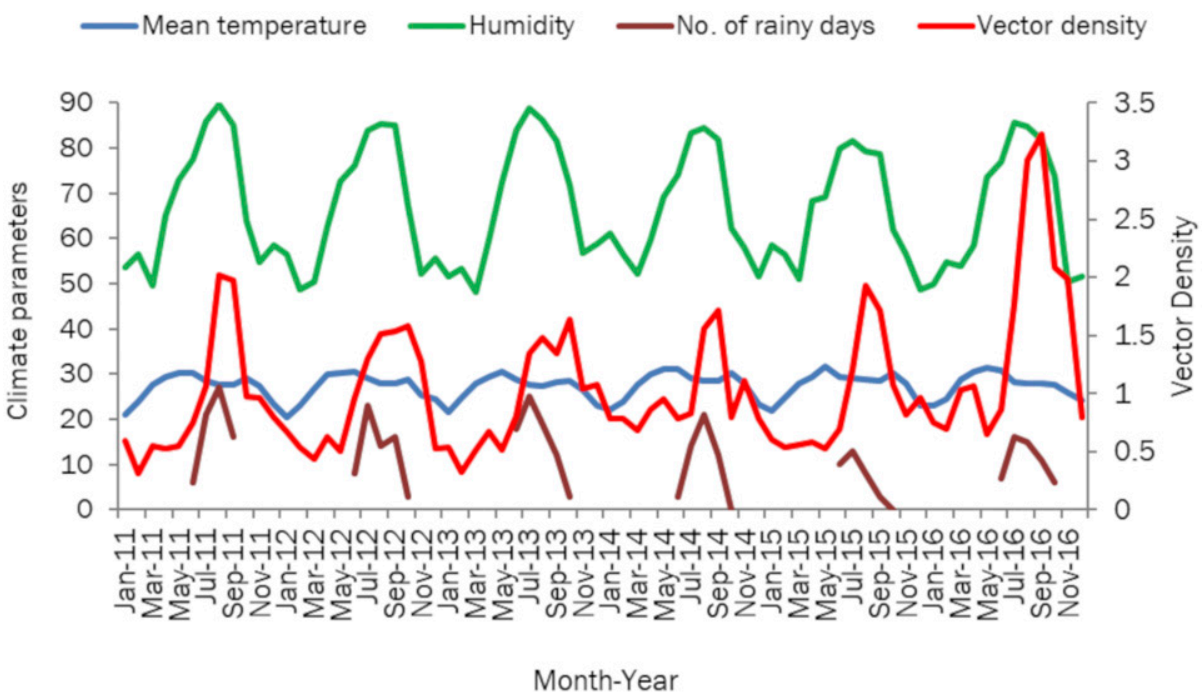

FIGURE 3. Relationship between climate parameters and female Aedes aegypti vector density (per 10 man-hour) in Surat city, Gujarat, India, 2011-2016. This figure appears in color at www.ajtmh.org. 
estimate the probable number of dengue cases that can help in planning appropriate preventive measures.

Received December 26, 2019. Accepted for publication March 18, 2020.

Published online April 20, 2020.

Note: Supplemental table appears at www.ajtmh.org.

Acknowledgments: We are extremely thankful to the Deputy Commissioner (Health \& Hospital department), Medical Officer of Health, and Vector-Borne Disease Control department for allowing access to the surveillance data for the research. The American Society of Tropical Medicine and Hygiene (ASTMH) assisted with publication expenses.

Authors' addresses: Viral R. Bajwala, Department of Health and Hospital, Surat Municipal Corporation, Surat City, India, E-mail: vrbdrvrb@gmail.com. Denny John, Campbell South Asia, New Delhi, India and ICMR-National Institute of Medical Statistics, New Delhi, India, E-mail: djohn1976@gmail.com. Daniel Rajasekar and Manoj V Murhekar, National Institute of Epidemiology, Indian Council of Medical Research, Chennai, India, E-mails: danielrosy@gmail.com and mmurhekar@gmail.com. Alex Eapen, Indian Council of Medical Research - National Institute of Malaria Research, Chennai, India, E-mail: alexeapen@yahoo.com.

\section{REFERENCES}

1. World Health Organization, 2019. Dengue Fact Sheet. Available at: https://www.who.int/news-room/fact-sheets/detail/dengue-andsevere-dengue. Accessed July 19, 2019.

2. Bhatt $S$ et al., 2013. The global distribution and burden of dengue. Nature 496: 504-507.

3. European Centre for Disease Prevention and Control, 2019. Dengue Cases Reported Worldwide as of 22 November 2019. Available at: https://www.ecdc.europa.eu/en/dengue-monthly. Accessed December 7, 2019.

4. National Vector Borne Disease Control Programme, 2019. Directorate General of Health Services Ministry of Health \& Family Welfare. Available at: http://www.nvbdcp.gov.in/index4.php? lang $=1 \&$ level $=0 \&$ linkid $=431 \&$ lid $=3715$. Accessed December 7, 2019.

5. World Health Organization, 2009. Dengue Guidelines for Diagnosis, Treatment, Prevention and Control. New ed. Available at: https:// www.who.int/tdr/publications/documents/dengue-diagnosis.pdf. Accessed July 10, 2019.

6. Tseng WC, Chen CC, Chang CC, Chu YH, 2009. Estimating the economic impacts of climate change on infectious diseases: a case study on dengue fever in Taiwan. Climatic Change 92: 123-140.

7. Woon YL et al., 2018. Estimating dengue incidence and hospitalization in Malaysia, 2001 to 2013. BMC Public Health 18: 946.

8. National Vector Borne Disease Control Programme, Government of India, 2015. National Guidelines for Clinical Management of Dengue Fever. Available at: http://www.nvbdcp.gov.in/ WriteReadData/1892s/Dengue-National-Guidelines-2014.pdf. Accessed July 10, 2019.

9. Tutiempo Network, SL, 2016. Available at: http://en.tutiempo.net/ climate/ws-428400.html. Accessed January 2, 2017.

10. IndianMeteorological Department, 2019. Available at: http:// imd.gov.in/section/nhac/wxfaq.pdf. Accessed August 6, 2019.

11. Pathak KB, Ram F, 1992. Techniques of Demographic Analysis. Chapter on Measures of Population Change and Distribution. Bombay, India: Himalaya Pub. House, 2.

12. Report: Task Force on Medical Education for the National Rural Health Mission, New Delhi, Ministry of Health and Family Welfare, Government of India. Available at: https://www.nhm.gov.in/images/ pdf/communitisation/task-group-reports/med-education.pdf. Accessed December 12, 2019.

13. Government of India, 2002. Tenth Five Year Plan 2002-07. New Delhi: Indian Planning Commission. Available at: http:// planningcommission.nic.in/plans/planrel/fiveyr/10th/volume2/ v2_ch2_8.pdf. Accessed December 12, 2019.
14. Ukey P, Bondade S, Paunipagar P, Powar R, Akulwar S, 2010. Study of seroprevalence of dengue fever in central India. Indian J Community Med 35: 517-519.

15. Chatterjee SS, Sharma A, Choudhury S, Chumber SK, Bage R, Parkhe N, Khanduri U, 2017. Dengue fever in a south Asian metropolis: a report on 219 cases. Iran J Microbiol 9: 174-185.

16. Thai KT, Nishiura H, Hoang PL, Tran NTT, Phan GT, Le HQ, Tran BQ, Nguyen NV, de Vries PJ, 2011. Age-specificity of clinical dengue during primary and secondary infections. PLoS Negl Trop Dis 5: e1180.

17. Egger JR, Coleman PG, 2007. Age and clinical dengue illness. Emerg Infect Dis 13: 924-925.

18. Anker M, Arima Y, 2011. Male-female differences in the number of reported incident dengue fever cases in six Asian countries. West Pac Surveill Response J 2: 17-23.

19. Panwala T, Mulla S, 2014. Is dengue emerging as a major public health problem in the southern region of Gujarat? $J$ Res Med Dental Sci 2: 69-73.

20. Chakravarti A, Kumaria R, 2005. Eco-epidemiological analysis of dengue infection during an outbreak of dengue fever, India. Virol J 2: 32.

21. Surat Municipal Corporation, 2015. Available at: https://www. suratmunicipal.gov.in/Departments/HydraulicPresentScenario. Accessed September 3, 2018.

22. Joint publication by National Institute of Communicable diseases, New Delhi and World Health Organization, 2006. Guidelines for Prevention and Control of Dengue. New Delhi, India: National Institute of Communicable Diseases, 12.

23. National Vector Borne Disease Control Program, India, 2016. Operational Guidelines for Urban VBDs Scheme. Delhi, India: National Vector Borne Disease Control Programme, Government of India, 51-52.

24. Stoddard ST et al., 2013. House-to-house human movement drives dengue virus transmission. Proc Natl Acad Sci U S A 110: 994-999.

25. Stoddard ST, Morrison AC, Vazquez-Prokopec GM, Paz Soldan V, Kochel TJ, Kitron U, Elder JP, Scott TW, 2009. The role of human movement in the transmission of vector-borne pathogens. PLoS Negl Trop Dis 3: e481.

26. Bowman LR, Runge-Ranzinger S, McCall PJ, 2014. Assessing the relationship between vector indices and dengue transmission: a systematic review of the evidence. PLoS Negl Trop Dis 8: e2848.

27. Goh KT, Ng SK, Chan YC, Lim SJ, Chua EC, 1987. Epidemiological aspects of an outbreak of dengue fever/dengue haemorrhagic fever in Singapore. Southeast Asian J Trop Med Public Health 18: 295-302.

28. Koh BKW, Ng LC, Kita Y, Tang CS, Ang LW, Wong KY, James L, Goh KT, 2008. The 2005 dengue epidemic in Singapore: epidemiology, prevention and control. Ann Acad Med Singapore 37: 538-545.

29. Chadee DD, 2009. Dengue cases and Aedes aegypti indices in trinidad, West Indies. Acta Trop 112: 174-180.

30. Pan American Health Organization, 1994. Dengue and Dengue Hemorrhagic Fever in the Americas: Guidelines for Prevention and Control. Washington DC: PAHO, Scientific Publication, 98, 548.

31. Scott TW, Amerasinghe PH, Morrison AC, Lorenz LH, Clark GG, Strickman D, Kittayapong P, Edman JD, 2000, Longitudinal studies of Aedes aegypti (Diptera: culicidae) in Thailand and Puerto Rico: blood feeding frequency. J Med Entomol 37: 89-101.

32. Mutheneni SR, Morse AP, Caminade C, Upadhyayula SM, 2017. Dengue burden in India: recent trends and importance of climatic parameters. Emerg Microbes Infect 6: e70.

33. Neuberger A, Turgeman A, Lustig Y, Schwartz E, 2016. Dengue fever among Israeli expatriates in Delhi, 2015: implications for dengue incidence in Delhi, India. J Travel Med 23: 1-2.

34. Shepard DS, Halasa YA, Tyagi BK, Adhish SV, Nandan D, Karthiga KS, Chellaswamy V, Gaba M, Arora NK; The Inclen Study Group, 2014. Economic and disease burden of dengue illness in India. Am J Trop Med Hyg 91: $1235-1242$

35. Bajwala VR, John D, Rajasekar TD, Murhekar MV, 2019. Severity and costs associated with hospitalization for dengue in public and private hospitals of Surat city, Gujarat, India, 2017-2018, Trans R Soc Trop Med Hyg 113: 661-669. 